\title{
EMANCIPACIÓN: BREVE RECORRIDO POR EL TÉRMINO
}

\author{
Alejandro Andreassi Cieri \\ Universitat Autònoma de Barcelona (UAB)
}

RESUMEN: En este artículo se realiza un recorrido etimológico e histórico del término emancipación, destacando las implicaciones sociales y políticas que dicho término ha tenido para significar coyunturas de conflicto y de cambio social, así como el papel que ha jugado en la representación de modelos sociales en el imaginario de los actores de esos procesos sociales, especialmente si se han desarrollado en el curso de la lucha de clases. Tácitamente, el artículo también atiende a una semántica que ha tenido gran importancia en el desarrollo de la cultura de la modernidad.

PalABras Clave: emancipación; movimientos sociales; procesos revolucionarios; pensamiento político y social; democracia; consejos obreros.

RESUM: Aquest article realitza un recorregut etimològic i històric del terme emancipació, s'hi destaquen les implicacions socials i polítiques que el dit terme han tingut per a significar conjuntures de conflicte i de canvi social, així com el paper que ha jugat en la representació de models socials en l'imaginari dels actors d'aqueixos processos socials, especialment si s'han desenvolupat en el curs de la lluita de classes. Tàcitament, l'article també atén una semàntica que ha tingut molta importància en el desenvolupament de la cultura de la modernitat.

Paraules Clau: emancipació; moviments socials; processos revolucionaris; pensament polític i social; democràcia; consells obrers. 
ABSTRACT: This article examines the historical and etymological meaning of "emancipation", highlighting the socio-political implications of the term for social and political actors in times of conflict and social change. It also discusses the role of emancipation in the representation of social models in the minds of the participants in these social processes, particularly in the context of class struggle. The article also tacitly deals with a semantics that has played a major part in the development of the culture of modernity.

KeYWORDs: emancipation, social movements, revolutionary processes, political and social thought, democracy, workers' councils.

$\mathrm{E}$ concepto tiene un largo recorrido histórico. Ferrater Mora lo considera sinónimo de liberación, de uso más habitual entre las culturas latinas, mientras que emancipación sería de uso común en las germánicas y anglosajonas: Emanzipation (Ferrater Mora, 1979). Su origen se remite al derecho romano y se refiere al momento en que el hijo abandonaba la autoridad paterna, adquiriendo la capacidad jurídica y autonomía para regir sus propios asuntos. Conserva, a través del tiempo, un carácter doméstico e individual. Recién entrado el siglo XVIII, con la Ilustración y la Revolución Francesa devendrá un término con significado político al referirse a la liberación colectiva de pueblos, clases o géneros de la dominación ejercida por otros grupos sociales o políticos. La Enciclopedia extiende su significado más allá del ámbito doméstico y del derecho civil para insinuar su pertinencia a los ámbitos social y político, ya que afirma que la emancipación es un acto en virtud del cual «ciertas personas quedan liberadas del poder de otros» (Brunner et al., 1984, p. 153). El célebre sapere aude — «atrévete a pensar»— de Kant, en su ensayo en el que explicaba qué era la Ilustración, es una llamada a la autonomía, a emanciparse del dominio de prejuicios y dogmas, de toda imposición arbitraria, aunque no utilice el término en su texto. Atreverse a pensar es no sólo una invitación a usar la razón, sino a usarla en un sentido radical, o sea, del que va a la raíz de lo que es objeto de su reflexión, ya que atreverse denota decisión de autonomía y, por lo tanto, rebelión contra lo estatuido, ya sea simbólica o materialmente. Si bien, la exhortación de Kant es general y 
dirigida a rechazar el conjunto de condiciones que obstaculizaban la plena vigencia de la autonomía humana, es un principio que inspira tácitamente a todos los movimientos sociales y políticos a partir del siglo XIX, ya que es una invitación al pensamiento crítico en el sentido más filosófico: contribuye a iluminar la realidad global y permite entender las razones, las raíces de los fenómenos analizados, y captar sus contradicciones (Munck, 2001, p. 311). Para los ilustrados en general, emancipación significaría la objetivación del ejercicio del derecho natural, ya que no sería una condición otorgada sino una condición innata de los seres humanos, un presupuesto ontológico. Incuso un autor como Herder, que actúa de puente entre la Ilustración y el romanticismo advertía que «[...] el hombre es el primer liberado de la Creación» (Cit. por Brunner et al., 1984, pp. 161-162). Es, por lo tanto, a partir del último tercio del siglo XVIII que el término «emancipación» adquiere un significado político e histórico-filosófico más allá de su origen en el ámbito del derecho privado.

Hasta ese momento el término emancipación, o su correlato latino liberación, hacían referencia a la libertad negativa, o sea a la ausencia de trabas en la actividad del individuo y el grupo. Pero ampliarán su significado para incluir la libertad positiva, o sea la capacidad de autonomía para realizar un proyecto de interés para quienes se emancipan. Esta concepción será progresivamente refinada y reforzada a partir de la propia experiencia de los trabajadores al comprobar que los mínimos espacios de ciudadanía que conseguían fuera del ámbito laboral eran negados sistemáticamente en dicho ámbito, donde el patrono continuaba ejerciendo su autoridad sin ninguna limitación (Domènech, 2004). Ilustrados y libertarios precoces como William Godwin en el último tramo del siglo XVIII comparaban la situación de los asalariados y especialmente del proletariado que generaba la incipiente revolución industrial con la de los sometidos a esclavitud o servidumbre, y por lo tanto de la propia caracterización de la situación de opresión deducían la necesidad de hablar de emancipación. Robespierre acuñó la divisa «Libertad, igualdad, fraternidad» en un discurso ante la Asamblea Nacional el 5 de diciembre de 1790. Esa divisa contiene los conceptos fundamentales que componen la emancipación. Pero Robespierre hizo algo más, al definir las condiciones materiales y objetivas para que dicha divisa se hiciera realidad, para que se concretara la ausencia de dominación, en su discurso a la Convención del 2 de diciembre de 1792: 
La primera ley social es aquella que garantiza a todos los miembros de una sociedad los medios de existencia; todas las otras están subordinadas a aquélla; la propiedad no ha sido instituida o garantizada más que para cimentarla; es en primer lugar para vivir que existen las propiedades. No es cierto que la propiedad pueda oponerse a la subsistencia de los hombres. Los alimentos necesarios al hombre son también tan sagrados como la vida misma. Todo lo que es indispensable para conservarla es una propiedad común de la sociedad entera [...] De acuerdo con este principio, ¿cuál es el problema a resolver en materia de legislación sobre las subsistencias?: asegurar a todos los miembros de la sociedad el disfrute de la porción de frutos de la tierra necesarios para su existencia, a los propietarios o cultivadores el precio de su actividad y dejar el excedente a la libertad de comercio [...] aprended a disfrutar de los encantos de la igualdad y las delicias de la virtud, o al menos conformaos con las ventajas que la fortuna os ha dado, y dejad al pueblo el pan, el trabajo y las costumbres. (Robespierre et al., 2000, p. 183).

Robespierre defendía una economía moral que permitiera a los pobres defenderse de la arbitrariedad y el autoritarismo de los poderosos, que recogía también la experiencia de esas clases sometidas, donde la noción de la justicia y de necesidad vital prevalece sobre las condiciones del mercado. Al garantizar el Estado y la sociedad a cada ciudadano los medios suficientes para su subsistencia se asegura la condición de no depender de la voluntad de otro para subsistir, por la posibilidad de ser libre en condiciones de equidad, que son asequibles si existe una solidaridad (fraternidad) entre los miembros de esa sociedad. Es importante notar que aquí Robespierre está considerando que la dominación, por lo tanto lo contrario a la libertad y autonomía que es el resultado de la emancipación, no necesariamente significa coerción física o psíquica, sino que puede interpretarse como dependencia de alguien. Ésta es la situación habitual no del esclavo, que es dominado mediante la coerción, sino del proletario, que depende de que alguien compre su fuerza de trabajo para poder sobrevivir. Justamente, Robespierre propone que cada miembro de la sociedad tenga asegurado el sustento material de su autonomía para no tener que depender de que alguien lo alquile para poder sobrevivir. Si lo tradujéramos al lenguaje actual, por ejemplo podríamos referirnos a la renta básica o la renta ciudadana garantizada como esas condiciones de posibilidad de la autonomía, aunque evidentemente la autonomía plena será la que alcance la sociedad humana cuando se haya emancipado de las relaciones 
sociales y políticas que sostienen la explotación del hombre por el hombre y con ello la sociedad de clases. Así también lo hace un autor actual como Quentin Skinner quien concibe dominación como dependencia:

[...] siempre será necesario que el Estado asegure al mismo tiempo que sus ciudadanos no caen en una condición evitable de dependencia de la buena voluntad de otros. El Estado tiene el deber no sólo de liberar a sus ciudadanos de esa explotación y dependencia personal, sino de impedir que sus propios agentes, investidos de una autoridad, se comporten arbitrariamente al imponer las reglas que gobiernan nuestra vida en común. (Skinner, 2001, p. 119)

El vínculo entre su significado originario y el que adoptará a partir de los siglos XVIII y XIX se produce porque los movimientos sociales y políticos que pretendían acabar con la dominación y explotación interpretaban su situación coyuntural sobre tres ideas que se complementaban. La primera: consideraban que la misma existencia de esas organizaciones que agrupaban a los trabajadores señalaba la adquisición por sus miembros de la mayoría de edad, un ejemplo de autonomía por medio del cual elaboraban objetivos sociales y políticos independientes e incluso contrarios a los de quienes dependían, de quienes los dominaban. Alcanzar la «mayoría de edad» significaba abandonar la dependencia, adquirir la autonomía y transformar las relaciones entre los seres humanos en relaciones no entre pater et filius, sino entre fratres, entre hermanos, por ello, al menos en la tradición libertaria que arranca con la Revolución Francesa, la emancipación está íntimamente vinculada a la idea de fraternidad. La loi famille, ${ }^{1}$ que es la que regía las relaciones de dominación-dependencia en el ámbito privado familiar, también englobaba las relaciones de dominación que se producían en el mundo de la economía y la sociedad civil del Antiguo Régimen. La segunda idea consistía en concebir las nuevas relaciones sociales establecidas en el incipiente capitalismo como una repetición de esa loi famille, vigente en el antiguo sistema gremial patriarcal y autoritario, al ámbito de la empresa industrial, que reproducía las mismas pautas de autoritarismo y jerarquía a pesar de las

1. Originariamente expresaba las relaciones que derivan del concepto clásico de familia, una voz que a su vez deriva de famuli — palabra que designaba al personal que servía en la residencia y explotación del pater familias, sobre las que el patriarca ejerce su total y absoluta autoridad, y no sólo a los miembros consanguíneos o vinculados por relaciones de parentesco. 
innovaciones tecnológicas que representaba. Ésta, como aquél, quedarían fuera del alcance de los derechos de ciudadanía, donde la única normatividad sería la que deriva de la autoridad incontestable del empresario que reproduciría en la empresa moderna la figura que desempeñaba el pater familias en la antigüedad clásica, reproduciendo las mismas relaciones de dependencia y sometimiento vigentes en la loi famille tradicional. Una situación que para los trabajadores asalariados no cambiaría demasiado con las economías de escala, las grandes corporaciones y la estructura burocrática que caracterizaron al «capitalismo organizado» que describieron Hilferding y Weber a comienzos del siglo xx y que constituyen el núcleo del capitalismo industrial hasta nuestros días. De alguna manera, podemos considerar esta situación una comprobación más de la «contemporaneidad de lo asíncrono» que Ernst Bloch señalaba como característica de la modernidad.

Es la propia naturaleza civil de la dependencia y el sometimiento la que promueve la aplicación de la metáfora familiar a la liberación de las clases subalternas, porque es la misma naturaleza del pensamiento económico liberal la que exige mantener a la esfera de la economía fuera del ámbito de lo político, cuando en realidad cualquier relación social en la que se establezca relación de dominación-dependencia son relaciones de carácter político. $\mathrm{La}$ razón por la cual el pensamiento económico liberal clásico (y el neoliberal actual) propugnan la estricta separación entre acción política — especialmente señalada en el Estado - y actividad económica, es su afán de señalar el carácter natural —y por lo tanto ajeno a la intervención humana intencional, ergo política - de las relaciones económicas y sociales propias del capitalismo. Relaciones que por ese carácter natural no deberían ser interferidas por la intervención artificial de la acción política, so pena de destruir los mecanismos automáticos de la economía de mercado y con ello deteriorar sus resultados y el bienestar de la población. A partir del siglo XIX, los que empiezan a organizarse colectivamente para defender los derechos de las clases subalternas comprenden por su propia praxis que las relaciones de explotación a las que están sometidos, aunque estén en el ámbito de lo privado, son de carácter político porque expresan relaciones de poder. Esa percepción facilita el desplazamiento del significado del término emancipación de lo que clásica y tradicionalmente se entendía vinculado a la relación paterno-filial, por lo tanto doméstica y privada, al ámbito de lo público en la medida en que en el ámbito 
de trabajo, especialmente desde el surgimiento del sistema fabril, la relación del patrono con sus obreros revestía y conservaba los mismos atributos de autoritarismo y de dominación que los que se establecían en el ámbito filial.

En general, la desaparición de las condiciones de servidumbre y de opresión del Antiguo Régimen no fue considerada por las clases trabajadoras como la asunción de una ciudadanía plena. Además de que los derechos político-electorales continuaron restringidos durante la mayor parte del siglo XIX y en la mayoría de los países europeos, y en general el sufragio universal fue una conquista posterior a la Primera Guerra Mundial (Therborn, 1977), la clase obrera industrial y los jornaleros agrícolas siguieron experimentando que nada o muy poco había cambiado en el ámbito del trabajo respecto a la situación de sometimiento a la autoridad patronal. Un liberal moderado como Karl Biedermann afirmaba en 1847, que a pesar de la abolición de la servidumbre en Alemania:

[...] un sentimiento de amargura y malestar se ha apoderado de las clases bajas, las que consideran su emancipación política y legal sólo como un medio obsequio de carácter dudoso, ya que no se complementa con una emancipación social. (Biedermann, 1847, p. 64)

No se trataba de una percepción de la explotación en términos de trabajo excedente apropiado por el capitalista, o al menos no era esta la única percepción, sino que se trataba de los mecanismos de coerción que acompañaban al proceso de trabajo, mecanismos de coerción que muchas veces los propios trabajadores consideraban no conexos con la necesidad del proceso de producción, ya que se trataba de medidas disciplinarias como multas, descuento de salarios o despido, todos aquellos procedimientos que se pueden englobar en el concepto de «control externo del proceso de trabajo», que se diferencia del trabajo a destajo, los métodos tayloristas o la producción fordista, métodos de control intrínsecamente vinculados al proceso de trabajo y a la tecnología utilizada en la industria y a la capacidad técnica del trabajador.

En ese sentido, esta percepción de los trabajadores dará lugar a la idea de la democracia industrial, que se transformará en un objetivo permanente del movimiento obrero europeo y americano hasta bien entrado el siglo xx. La vigencia de ese agravio comparativo, por ejemplo, está muy presente en la revolución alemana de noviembre de 1918 que produjo el final del Imperio y 
el advenimiento de la República de Weimar, durante la cual una de las exigencias del movimiento obrero organizado en el Rätebewegung (movimiento consejista) era la de al menos limitar, si no abolir, el dominio patronal irrestricto en las empresas. Incluso se concebía el socialismo como algo estrechamente vinculado a la autogestión obrera en la empresa, tal como declaraba Heinrich Schliestedt, un delegado de los obreros metalúrgicos en el Congreso de los Consejos de Obreros y Soldados, celebrado en Berlín en diciembre de 1918 (Barrington Moore, 1978, p. 323). Incluso podría verse el momentáneo apoyo inicial de una parte considerable de los obreros alemanes a las propuestas de constituir un sistema de soviets, propuesto por el KPD, no en una aspiración de reproducir miméticamente las transformaciones revolucionarias que se estaban operando en Rusia, sino en la misma exigencia obrera de democratizar el sistema industrial, y fue una de las reivindicaciones de las masivas huelgas de la región del Ruhr de enero de 1919 (Mommsen, 1996, pp. 44-49). Con similar perspectiva observaba Gramsci al movimiento de ocupación de fábricas, en Turín, en septiembre de 1920, que constituyó los consejos de fábrica, al que consideraba como el embrión de la futura sociedad emancipada del dominio del capital, ya que la revolución se consumaría en tanto en cuanto la democracia, entendida como ejercicio del poder por los iguales, debía también verificarse en las entrañas del sistema económico, o sea en las fábricas, talleres y en todos los ámbitos de la producción y la circulación (Domènech, 2004, pp. 247-248; Pala et al., 2014, p. 276). Escribía Gramsci que:

Se halla enraizada en las masas la convicción de que el Estado proletario está encarnado en un sistema de consejos obreros, campesinos y de soldados [...] La existencia del Consejo confiere a los obreros la responsabilidad directa de la producción, les lleva a mejorar su trabajo, instaura la disciplina consciente y voluntaria, crea la psicología del productor, del creador de historia. (Gramsci, 1973, p. 33 y 40)

Por supuesto que reivindicaciones de control obrero de las relaciones laborales también se manifestaron con fuerza durante la revolución rusa, desde febrero a octubre de 1917, pero avanzaron más allá del ámbito del trabajo para construir un contrapoder al gobierno provisional en forma de consejos junto a los consejos de soldados y campesinos — soviets - (Barrington Moore,1978, pp. 369-370). 
La tercera idea es que esa emancipación, en la actual situación de las clases subalternas bajo el capitalismo, sólo se verificará mediante un cambio revolucionario. Por ello, el término emancipación comienza a ser habitual en las primeras organizaciones obreras y socialistas como la Liga de los Comunistas, en el período revolucionario de 1848. En su análisis de las jornadas revolucionarias de 1848 en Francia, Marx utiliza el término emancipación para caracterizar a las organizaciones del movimiento obrero:

A la Comisión del Luxemburgo, esta criatura de los obreros de París, corresponde el mérito de haber descubierto desde lo alto de una tribuna europea el secreto de la revolución del siglo xIx: la emancipación del proletariado [...] por muy diverso que fuese el socialismo de los diferentes grandes sectores que integraban el partido de la anarquía - según las condiciones económicas de su clase o fracción de clase y las necesidades generales revolucionarias que de ellas brotaban-, había un punto en que coincidían todos: en proclamarse como medio para la emancipación del proletariado [sic] y en proclamar esta emancipación como su fin. (Marx, 1975, p. 198)

Y vuelve a referirse a la emancipación para caracterizar su contenido revolucionario en el preámbulo de los Estatutos provisionales de la Asociación Internacional de Trabajadores:

Considerando que la emancipación de la clase obrera debe ser obra de la propia clase obrera; que la lucha por la emancipación de la clase obrera no es una lucha por privilegios o monopolios de clase, sino por el establecimiento de derechos y deberes iguales y por la abolición de todo dominio de clase; que el sometimiento económico del trabajador a quienes se han apropiado de los medios de trabajo, es decir, de las fuentes de vida, es la base de la servidumbre en todas sus formas, de toda miseria social, degradación intelectual y dependencia política; que la emancipación económica de la clase obrera es, por lo tanto, el gran fin al que todo movimiento político debe ser subordinado como medio [...] que la emancipación de la clase obrera no es un problema local ni nacional sino un problema social que implica a todas las naciones en la que existe la sociedad moderna. (Marx, 1962, p. 14)

Donde, al hablar de emancipación económica, está aplicando el mismo concepto de base material para la libertad, ya que la condición de su emancipación política es su emancipación social, de lo que deduce que el movimiento político se subordina a aquel objetivo al que Marx considera definitivo. Es un concepto que repetirá poco después en su análisis de la Comuna de 1871, 
cuando considere a esta como «...la forma política al fin descubierta para llevar a cabo, dentro de ella, la emancipación económica del trabajo» (Marx, 1976 b, p. 70). Pero al mismo tiempo, Marx está planteando que la emancipación no es simplemente la equiparación de derechos de los trabajadores con las clases propietarias, sino la transformación radical y revolucionaria de la sociedad, donde la emancipación de la clase obrera se alcance con la desaparición de las clases sociales y con ella el fin de la explotación y dominación de los trabajadores (Brunner et al., 1984, p. 194). Para acabar de delinear lo que para Marx significa la emancipación del dominio capitalista es necesario precisar que es lo que dicha emancipación niega: la alienación. En los Manuscritos de 1848 Marx define claramente en qué consiste uno de los efectos centrales del capitalismo, la alienación, en la cual el trabajo vivo es dominado y sometido por el trabajo muerto, o sea, donde el trabajador, al ceder su capacidad de concebir el objeto y proceso de su trabajo al empresario en el momento en que éste le alquila su capacidad de trabajar, pasa a depender del objeto de su trabajo, la mercancía que produce que se le presenta como algo ajeno a él, algo sobre lo que ha perdido el control.

Para Marx, la alienación — supresión de la libertad - consiste en la pérdida de las características propias del ser humano, recuperables en el proceso de liberación y des-alienación (con cuya consumación su esencia coincidirá con su existencia), pero al mismo tiempo, esas características, fundamento de una ontología social o antropología humanas, son moduladas por las realizaciones históricas del hombre en un tiempo y sociedad concretas (Prior Olmos, 2004, pp. 82-83). No es sólo un problema de naturaleza jurídico-política, sino que está vinculado estrechamente a la forma en que se produce y realza la actividad humana por excelencia bajo el capitalismo: el trabajo, que es el lugar en donde los ciudadanos experimentan cotidianamente su explotación y sometimiento. Por estas razones, para Marx lo opuesto a la emancipación será la alienación, que es una negación de la potencialidad y de la plasticidad humanas.

En el pensamiento anarquista el concepto de emancipación pretende adquirir un alcance mayor que el señalado por el marxismo, al indicar que no sólo se trata de la emancipación económica sino también de la cultural y 
sexual, en el sentido de la abolición de los tabúes y represiones establecidas por la sociedad burguesa. Como escribe Ricardo Mella:

Libertad política o de acción, libertad económica y libertad religiosa. Que cada uno pueda gobernarse a sí mismo. Que cada uno pueda entrar en conciertos libres con los demás en cuanto atañe a la producción, al cambio, al cambio, al consumo [...]. Que cada uno pueda rendir culto en su conciencia a lo que quiera o como quiera. No más poderes ni más privilegios, no más autoridad constituida, no más monopolio de la riqueza, no más poder religioso. Que la libertad, en toda su extensión, sea nuestro constante ideal. (Cit. por Álvarez Junco, 1991, p. 20)

La gran transformación semántica se manifiesta también en la conjugación reflexiva del verbo emancipar, que significa la asunción plena de que se trata de un proceso político de autoliberación y autoconfiguración de los sometidos y no de un cambio de condición jurídica otorgado por un tercero, como tradicionalmente se lo interpretaba (Brunner et al., 1984, p. 165). Es por todo ello que el concepto emancipación, en estos términos, será producto de las luchas sociales y políticas que se inician en la primera mitad del XIX, será un sinónimo de la aparición de la moderna lucha de clases y será objeto de la interpretación y el análisis de Marx y Engels, así como de la mayoría de pensadores del movimiento obrero que comienza su andadura en esa época. Para Marx, la culminación de la emancipación humana consistiría en la superación del reino de la necesidad para alcanzar el estadio en que para los seres humanos el desarrollo de sus propias fuerzas constituye un fin en sí mismo (Marx, 1976 a, p. volumen 8, 1044). Gramsci afirma que en el siglo XIX se desarrolla la «consciencia de la libertad», «[...] se hace historia sabiendo lo que se hace, sabiendo que la historia es historia de la libertad» (Gramsci, 1999, p. t. 4, 130). Agrega que en esa época aparece abarcando un amplio abanico de posiciones políticas y sociales el término «liberalismo», que reúne a todos aquellos que se oponen al clericalismo, al «partido del Sillabo [Syllabus]», y señala que esto justamente hace que el término incluya a «[...] los internacionalistas». Con ello viene a confirmar que el concepto de lucha por la libertad, y por lo tanto por la emancipación, está «ampliado» más allá de las clases o de las elites que en el Antiguo Régimen se ocupaban de lo político para abarcar al naciente movimiento obrero.

En el pensamiento occidental emancipación ha denotado siempre autoliberación, o sea, supresión de la dominación por la acción de los sometidos. 
Por ello, en el caso del esclavismo practicado por las potencias coloniales durante el siglo XVIII y por Estados Unidos, el Imperio del Brasil hasta el XIX y España se ha hablado más que de emancipación, de abolición de la esclavitud, ya que se consideraba que los esclavos devenían hombres libres a partir de una acción externa al propio grupo de esclavos, es decir, mediante una modificación legal realizada por los propios estados esclavistas. Sólo en el caso de la abolición de la esclavitud durante la guerra civil norteamericana se utilizó la palabra emancipación, tal cual figura en la proclamación de Lincoln que prologa el texto legal de la abolición de la esclavitud: Preliminary Emancipation Proclamation, de 1862 (Brunner et al., 1984, pp. 195-196). Sin embargo, sí que cabe hablar de emancipación en la gesta de los esclavos haitianos que, bajo la dirección de Toussaint Louverture, consiguieron librarse con su insurrección victoriosa del yugo establecido por los plantadores franceses, que culminó luego de varios enfrentamientos con la victoria de Jean-Jacques Dessalines sobre las tropas francesas enviadas por Napoleón con el objetivo de restaurar la esclavitud.

El racismo generado por el esclavismo no desaparecerá con la abolición de éste y será un factor condicionante en la lucha de clases por la emancipación de los trabajadores. El racismo, y en general la xenofobia, actuarán como factores de división de la necesaria unidad entre trabajadores de distintas culturas, etnias o nacionalidades, una división que será promovida por los empresarios y agentes gerenciales de las empresas afectadas por los conflictos y actuarán como complemento de la represión organizada desde las instituciones estatales. Marx se referirá en su momento al factor divisorio que jugarán los prejuicios de los obreros británicos respecto a sus camaradas irlandeses en la clase obrera británica, identificando esa división como un factor de su «impotencia» como clase:

Cada centro industrial y comercial de Inglaterra cuenta con una clase obrera dividida en dos campos hostiles: los proletarios ingleses y los proletarios irlandeses. El trabajador inglés normal odia al trabajador irlandés, al que ve como un competidor que empeora su forma de vida. En relación con el obrero irlandés, se ve a sí mismo como un miembro de la nación dominante y se convierte en una herramienta en manos de los aristócratas y capitalistas contra Irlanda, reforzando así el dominio de aquellos sobre símismo. Abriga los prejuicios religiosos, sociales y nacionales contra el trabajador irlandés. Su actitud hacia éste es similar a la de 
los «blancos pobres» con los negros en los estados ex-esclavistas de los EEUU. El irlandés le paga a su colega inglés con la misma moneda. Ve en el trabajador inglés a un cómplice y una estúpida herramienta de los dominadores ingleses de Irlanda. La prensa, el púlpito, las revistas cómicas, en pocas palabras, todos los medios a disposición de la clase dirigente mantienen a este antagonismo artificialmente vivo. Este antagonismo es el secreto de la impotencia de la clase obrera inglesa, a pesar de su organización. Es el secreto mediante el cual la clase capitalista mantiene su poder, y del cual es completamente consciente. (Marx \& Engels, 1975)

Por supuesto, como lo adelanta la cita, esa división y enfrentamiento racial se observarán también en el siglo xx. Por ejemplo, será una situación frecuente entre los trabajadores norteamericanos, especialmente en los estados del sur, mediante los sistemas de remuneración diferenciados, percibiendo los trabajadores negros un salario inferior - además de estar privados de derecho civiles — ${ }^{2}$ a los blancos, así como la misma discriminación laboral hacía que los niveles de desempleo fueran mucho mayores entre los afroamericanos. De ello se aprovechaban los empleadores para recurrir a esas bolsas de parados para reclutarlos como esquiroles en casos de huelga. Ello generaba un círculo vicioso en el cual la contratación temporal de afroamericanos provocaba el consiguiente repudio de los trabajadores en huelga, aumentado así el foso entre ambos grupos de trabajadores en el cual los prejuicios raciales eran al mismo tiempo causa y consecuencia. Esa política laboral de confrontación racial estimulada por las empresas contribuía a promover un sentimiento de superioridad de los trabajadores blancos respecto de sus compañeros negros, que a su vez retroalimentaba los prejuicios que los separaban. Si bien prevalecía la confrontación, en ciertas circunstancias la unidad de los trabajadores superaba los prejuicios y recelos. En esas ocasiones era posible no sólo la superación de esas barreras, sino también que se produjera un cambio en la percepción que los trabajadores poseían sobre las relaciones con sus compañeros afroamericanos y cuáles eran las verdaderas relaciones de poder y dominación que causaban la desigualdad que afectaba a todos, como sucedió en las huelgas generales

2. Si bien en 1870 la $15^{\mathrm{a}}$ Enmienda permitió el voto a la población afroamericana, en los estados del sur sólo fue efectiva a partir de la Voting Rights Act de 1965, que eliminaba además la exigencia de pruebas de alfabetización para poder votar y el Título vir de la Civil Rights Act de 1964 prohibía la discriminación racial en los puestos de trabajo. 
de la minería en Alabama en 1920, donde participaron conjuntamente mineros blancos y negros, y donde los patronos para derrotar a los huelguistas recurrieron incluso a la intervención del ejército y la declaración de la ley marcial (Kelly, 2001, pp. 179-186). Al mismo tiempo, para los mineros afroamericanos la unidad con los mineros blancos reforzaba su posición para reivindicar no sólo derechos laborales sino también derechos civiles, como sucedió durante la década de 1930, bajo los auspicios del New Deal (Woodrum, 2007, pp. 50-51). La polarización que se alcanzaba en algunos de estos conflictos ejemplifican, a la manera de E. P. Thompson, cómo la clase no es más que una relación social, una experiencia dinámica que se construye a través de la experiencia del conflicto que permite identificar las verdaderas fuentes del poder y las causas de la exclusión-padecimiento de quienes se enfrentan a ese poder, así como transitar la experiencia de la fraternidad, de tal modo que permite superar prejuicios y recelos, una manifestación de autonomía y autoorganización, precondiciones de la emancipación (Thompson, 1977, p. 8).

Hasta ahora nos hemos referido a las luchas por la emancipación centradas en la cuestión de clase suscitada por el desarrollo capitalista a partir de la revolución industrial. Corresponde agregar al panorama otros conflictos que se alinean pero que poseen un perfil propio respecto a la cuestión social propiamente dicha. Me refiero a las luchas por la emancipación de género que adquieren presencia intelectual y organizativa casi simultánea con la aparición de las primeras organizaciones obreras, y que ofrecen otra perspectiva, no antagónica y sí complementaria, desde la que observar la lucha por la emancipación de la especie humana. En 1792 se publica el texto de Mary Wollstonecraft, Vindicación de los derechos de la mujer, donde propone una lectura de la situación de la mujer que mantendrá su vigencia hasta nuestros días: la emancipación femenina es la respuesta a una doble opresión que padecen: la de género y la de clase. Wollstonecraft vinculó su prédica feminista a la emancipación de todos los oprimidos, vinculándolo al radicalismo social (Thompson, 2000, p. 93). Un mensaje similar difundió Flora Tristán en la Francia de 1830, quien a su vez había tomado contacto con el movimiento obrero británico y especialmente con el owenismo durante su estancia en Gran Bretaña, que plasmó en la idea de la Unión Obrera que propuso en 1843 (Historia general del socialismo, 1976, p. 543 y 626 -De los orígenes a 1875). Marx y Engels recogerán en La Sagrada Familia y repetirán en numerosas 
ocasiones la afirmación de Fourier: «Los progresos sociales y los cambios de períodos se operan en razón directa del progreso de las mujeres hacia la libertad; y las decadencias del orden social se operan en razón del decrecimiento de la libertad de las mujeres» (Marx \& Engels, 1989, p. 215). La socialdemocracia se ocupó de la cuestión femenina, siendo notable el impacto del libro de Bebel Die Frau und die Sozialismus, considerado extremadamente liberal incluso en los medios del movimiento obrero, pero fue un reflejo de la importancia que había adquirido la lucha por los derechos de las mujeres en Alemania y otros países. Sin embargo, el movimiento obrero socialdemócrata insertó la problemática de género en el marco general de la lucha por el socialismo, de tal modo que consideraba que la igualdad entre ambos sexos sería una consecuencia de la supresión de la propiedad privada y del trabajo asalariado. Esta postura era compartida por las militantes socialistas hasta el punto de que Clara Zetkin planteaba que:

La emancipación de la mujer proletaria no puede ser el resultado del esfuerzo de las mujeres de todas las clases sino sólo de la lucha de todo el proletariado sin distinción de sexos. (Brunner et al., 1984, p. 190-191)

Este planteamiento es rechazado hoy en día por los movimientos feministas que consideran que la igualdad de género no depende exclusivamente del cambio radical del sistema económico, pero que no siempre se puede establecer una separación tan taxativa entre la lucha por la emancipación social y la de género. Existen situaciones, como la de las mujeres negras norteamericanas, donde la opresión de género está íntimamente vinculada a la persistencia del racismo y como consecuencia a su relegación social son condenadas a ocupar las tareas de menor cualificación y menos valoradas. Por lo tanto, tienen que enfrentarse a una triple opresión que obliga a que la superación de una de ellas exija simultáneamente la de las otras. La lucha por los derechos civiles de los años sesenta, donde la participación femenina fue importantísima, es una demostración de este aserto (Davis, 2004; Zinn, 1997, p. 466 y sig.).

Hasta aquí la reflexión sobre las características genéticas y evolutivas del concepto emancipación. Pero su análisis histórico no debe detenerse ahí, sino que debe continuar con las circunstancias del presente, o sea, situar la cuestión emancipadora en el marco de la coyuntura histórica actual. La consu- 
mación de la emancipación, concebida como conquista de la autonomía y de la mayoría de edad de los humanos, exige actualmente la atención de otras consideraciones que no estaban vigentes o al menos no advertidas en épocas anteriores. Para los movimientos sociales del siglo xIX y la primera mitad del siglo xx aquélla se conquistaba mediante la abolición del capitalismo como sistema económico y se sustituía por una radical modificación de las relaciones sociales que conduciría a la abolición de la explotación del trabajo salariado que está en la base de dicho sistema, iniciándose la construcción de una sociedad sin clases. En realidad, Marx, y con él otros pensadores como Bujarin o Christopher Caldwell en los años treinta del siglo xx, ya reflexionaban sobre ello cuando consideraban que la emancipación humana, al suprimir las condiciones de opresión y explotación, debe suprimir las condiciones de depredación que constituye la explotación devastadora de la Naturaleza por el capitalismo (Foster, 2004, p. esp. 342-383). No sólo porque consume recursos energéticos y altera el ecosistema, sino porque en esa acción afecta y deteriora a los seres humanos, que son parte inherente de ese ecosistema. Por lo tanto, la emancipación humana implica liberación simultánea de la naturaleza oprimida por la acción humana, restableciéndose como relación armónica especie humana-ecosistemas en los que ambos interactúan en una relación de retroalimentación negativa u homeostática, lo que significa en primer término reconocer por la sociedad emancipada la limitación y finitud del medio natural en el que vive, y por lo tanto los flujos de energía deben estar compensados; debe entrar en el cálculo social el segundo principio de la termodinámica. Éste también es un rasgo de que la especie humana ha alcanzado su mayoría de edad, por lo tanto, de que la sociedad se ha emancipado efectivamente. Dice del comunismo como culminación de esa emancipación humana:

El comunismo como superación positiva de la propiedad privada en cuanto autoextrañamiento del hombre, y por ello como apropiación real de la esencia humana por y para el hombre; por ello como retorno del hombre para sí en cuanto hombre social, es decir, humano; retorno pleno, consciente y efectuado dentro de toda la riqueza de la evolución humana hasta el presente. Este comunismo es, como completo naturalismo = humanismo, como completo humanismo $=$ naturalismo; es la verdadera solución del conflicto entre el hombre y la Naturaleza, entre el hombre y el hombre, la solución definitiva 
del litigio entre existencia y esencia, entre objetivación y autoafirmación, entre libertad y necesidad, entre individuo y género. (Marx, 1989, p. 143)

En la actualidad se ha operado un cambio en las perspectivas que la ha hecho más compleja, ya que se considera que el sistema, basado en el productivismo, y en consecuencia el consumo de recursos naturales sin límites, ha producido un grave deterioro en las condiciones materiales para la reproducción de la vida humana debido a su carácter depredador de los ecosistemas, creando una gravísima crisis que se manifiesta por el cambio climático, el agotamiento de las fuentes de energía y la contaminación. Ello supone a los movimientos emancipatorios la exigencia de incluir estos efectos de la actual organización de la civilización planetaria entre los aspectos a incluir en el diagnóstico de situación y, por lo tanto, a considerar que las relaciones sociales y políticas que sustituyan a las propias del capitalismo deberán tener en cuenta también las relaciones que los seres humanos deben establecer con la Naturaleza, de la cual - aunque a veces pareciera que lo olvidáramosformamos parte. Ese cambio de relaciones exige un nuevo ethos, una nueva cultura que tenga en la autolimitación del consumo de recursos una de sus condiciones, que sepa aplicar el freno a la maquina desbocada del llamado progreso como planteaba Walter Benjamin en su IX Tesis de filosofía de la historia.

Ello justamente revalida, al final del ciclo histórico, la recuperación de aquellos principios ilustrados sobre la ética y la responsabilidad que deben acompañar el ejercicio de la autonomía conquistada con la emancipación. Por lo tanto, en la actualidad sería parte inherente de un movimiento emancipatorio la reivindicación, por una parte, de la vigencia actual del imperativo categórico de Kant que reza: «Actúa de forma tal que uses la humanidad, tanto en tu persona como en la persona de cualquier otro, siempre al mismo tiempo como un fin y nunca meramente como un medio», que define una conducta antagónica a la que impone el capitalismo con su razón instrumental y su utilización del ser humano como mero medio para la acumulación y valoración incesante del capital. Pero también su actualización, tal como hace Hans Jonas, al enunciarlo como: «Actúa de un modo tal que los efectos de tu acción sean compatibles con la permanencia de una vida humana auténtica en la Tierra» (Negt, 2004, pp. 79-80). Una actualización que es el resultado, no 
de modificar nuestra concepción sobre las características de la civilización del capitalismo, sino de ampliar la perspectiva, porque ahora hemos comprobado que la inhumanidad del modo de producción no se manifestaba sólo en las condiciones de explotación del trabajo asalariado, sino en la amenaza directa sobre las condiciones de vida al conocer sus efectos nocivos sobre el medio que se han desplegado ahora en una dimensión que era muy difícil de concebir o prever en el siglo XIX.

\section{Referencias}

Álvarez Junco, J. (1991): La Ideología politica del anarquismo español (1868-1910) (2a ed.), Siglo Xxi de España, Madrid.

Barrington Moore, Jr. (1978): Injustice: The Social Bases of Obedience and Revolt (New edition edition), White Plains, N.Y., Routledge, New York.

Biedermann, K. (1847): Vorlesungen über Sozialismus und soziale Fragen. Leipzig.

Brunner, O.; W. Conze \& R. Koselleck (1984): Geschichtliche Grundbegriffe (1. Aufl.), Klett, Stuttgart.

DAVIS, A. (2004): Mujeres, raza y clase, Akal, Madrid.

DoMÈNECH, A. (2004): El eclipse de la fraternidad: una revisión republicana de la tradición socialista, Crítica, Barcelona.

Ferrater Mora, J. (1979): Diccionario de filosofía, Alianza, Madrid.

Foster, J. B. (2004): La ecología de Marx: materialismo y naturaleza, Ediciones de Intervención Cultural, Barcelona.

Gramsci, A. (1973): Consejos de fábrica y estado de la clase obrera, Ediciones Roca, México DF.

Gramsci, A. (1999): Cuadernos de la cárcel, Era/Buap, México.

Kelly, B. (2001): Race, Class, and Power in the Alabama Coalfields, 1908-21, University of Illinois Press, Urbana.

MARx, K. (1962): Provisorische Statuten der Internationalen Arbeiter-Assoziation. En $M E W$ (Vol. Bd. 18, pp. 14-16), Dietz Verlag, Berlin.

MARx, K. (1975): Las luchas de clases en Francia. Ayuso, Madrid. 
MARx, K. (1976 a): El Capital: crítica de la economía política (3 ${ }^{\text {a }}$ ed.), Siglo XXI, Madrid.

Marx, K. (1976 b): La guerra civil en Francia, Aguilera, Madrid.

MARx, K. (1989): Manuscritos: economía y filosofia, Alianza Editorial, Madrid.

Marx, K. y F. Engels. (1975): Selected correspondence. Progress Publishers. Recuperado a partir de <https://www.marxists.org/archive/ marx/works/1870/letters/70_04_09.htm>.

Marx, K. y F. Engels. (1989): La sagrada familia, Adgena, Barcelona.

Mommsen, H. (1996): The Rise and the Fall of Weimar Democracy, University of North Carolina Press, Chapel Hill.

Munck, T. (2001): Historia social de la Ilustración, Editorial Crítica, Barcelona.

Negt, O. (2004): Kant y Marx: un diálogo entre épocas, Editorial Trotta, Madrid.

Pala, G.; A. Firenze \& J. Mir García (2014): Gramsci y la sociedad intercultural, Montesinos/Ediciones de Intervención Cultural, Vilassar de Dalt.

Prior Olmos, A. (2004): El problema de la libertad en el pensamiento de Marx. Editorial Biblioteca Nueva, Madrid.

Robespierre, M. De; Y. Bosc ; F. Gauthier y S. Wahnich (2000): Pour le bonheur et pour la liberté: discours, Éd. la Fabrique. Paris.

Skinner, Q. (2001): Liberty before liberalism, Cambridge University Press, Cambridge/New York.

Therborn, G. (1977): «The Rule of Capital and the Rise of Democracy», New Left Review, (103), 3-41.

Thомpson, E. (1977): La formación histórica de la clase obrera: Inglaterra: 1780-1832, Editorial Laia, Barcelona.

Thompson, E. P. (2000): Agenda para una historia radical, Crítica, Barcelona.

VvaA (1976): Historia general del socialismo, Destino, Barcelona.

Woodrum, R. H. (2007): Everybody Was Black Down There: Race and Industrial Change in the Alabama Coalfields (annotated edition edition), University of Georgia Press, Athens.

ZinN, H. (1997): La otra historia de los Estados Unidos, Argitaletxe Hiru, Hondarribia. 
